\title{
BMJ Open Current management of atrial fibrillation: an observational study in NHS primary care
}

\author{
George Kassianos, ${ }^{1}$ Chris Arden, ${ }^{2}$ Simon Hogan, ${ }^{3}$ Robert Dew, ${ }^{4}$ Ahmet Fuat ${ }^{5}$
}

To cite: Kassianos $\mathrm{G}$, Arden C, Hogan S, et al. Current management of atrial fibrillation: an observational study in NHS primary care. BMJ Open 2013;3:e003004. doi:10.1136/bmjopen-2013003004

- Prepublication history for this paper is available online. To view these files please visit the journal online (http://dx.doi.org/10.1136/ bmjopen-2013-003004).

Received 5 April 2013 Accepted 16 October 2013

CrossMark

\footnotetext{
${ }^{1}$ The Ringmead Medical Practice, Bracknell, UK ${ }^{2}$ Park Surgery, ChandlersFord, UK

${ }^{3}$ Sanofi UK, Guildford, UK

${ }^{4} \mathrm{pH}$ Associates Ltd, Marlow, UK

${ }^{5}$ Carmel Medical Practice, Darlington, UK
}

Correspondence to Dr George Kassianos; gckassianos@btinternet.com

\section{ABSTRACT \\ Objective: To describe National Health Service (NHS) resource use and pharmacological management of atrial fibrillation (AF) in routine UK primary care. \\ Design: Multicentre retrospective study. \\ Setting: Seven primary care practices in England, one in Wales. \\ Patients: Patients with AF were identified and approached for consent. Data were collected on the first 12 weeks post-diagnosis ('initiation') and, for established patients, up to the most recent 3 years of management ('maintenance').}

Results: Data collected on 825 patients with AF, $56 \%$ men. Mean age (at diagnosis) 70.5 years. Mean 2.4 (SD 2.2) visits to primary care per patient during the initiation phase; 1.5 (SD 1.8) per patient-year during the maintenance phase. Mean 0.4 (SD 0.6) inpatient admissions for AF per patient during the initiation phase and 0.1 (SD 0.3) per patient-year during the maintenance phase. The mean length of hospital stay per admitted patient was 5.6 days during initiation and 6.4 days per patient-year during maintenance. During the initiation phase, $46.1 \%(143 / 310)$ patients received a $\beta$-blocker and $97(31.3 \%)$ received no rate/rhythm control. Only $234(75.5 \%)$ patients received thromboprophylaxis in the 12 weeks postdiagnosis and $674(87.7 \%)$ in the maintenance phase. $440(57.2 \%)$ patients were deemed to be at high risk of stroke at the end of the maintenance phase; $55 \%$ (242/440) of these were receiving appropriate anticoagulation therapy.

Conclusions: The results suggest that there are opportunities for optimisation of treatment and there is significant NHS resource associated with $\mathrm{AF}$ management, the details of which are invaluable for future healthcare planning and policy development in this area.

\section{INTRODUCTION}

Atrial fibrillation (AF) is a common arrhythmia, with an estimated UK prevalence of $8 \%$ in the over $75 \mathrm{~s} .{ }^{1}$ This has increased in recent decades $^{2}$ and is predicted to increase further, partly due to the growing elderly population. ${ }^{3}$

The main goal of treatment for $\mathrm{AF}$ is stroke prevention ${ }^{4}$; the annual risk of stroke

\section{Strengths and limitations of this study}

- The primary strength of this study is that it describes 'real world' UK clinical practice in primary care management of atrial fibrillation including healthcare resource use, management pathway and pattern of treatments.

- A limitation of the study is that the actual sample size achieved was lower for the initiation group but higher for the maintenance group as the study relied on retrospective methodology with patient consent for researchers to access these records.

- Resource use may be underestimated due to the exclusion of deceased patients or those unable to provide consent as the terms of the Research Ethics Committee approval did not extend to collection of data on these groups of patients.

is 5-6 times greater in patients with $\mathrm{AF}$ than in people with a normal heart rhythm. ${ }^{5}$ Individual risk depends on additional risk factors such as age, diabetes, hypertension, vascular disease and previous thromboembolism or ischaemic stroke. In 2006, the National Institute for Health and Care Excellence (NICE) recommended warfarin for stroke prevention in patients with $\mathrm{AF}$ with moderate or severe risk, and antiplatelets for those with no additional risk factors. ${ }^{6}$ Reinforcing this, the Quality and Outcomes Framework (QOF) criteria for stroke prevention in patients with $\mathrm{AF}^{7}$ now include two indicators relating to the appropriate prescribing of antithrombotics according to the $\mathrm{CHADS}_{2}$ stroke risk-scoring tool. ${ }^{8}$

Improvement of cardiac function is also an important treatment goal with two general approaches: 'rate control', allowing the patient to remain in AF but controlling the ventricular response with either atrioventricular (AV) nodal blocking agents or AV junction ablation, and 'rhythm control', using antiarrhythmic medications or ablation.

Overall, AF management represents a significant and potentially increasing burden to 
healthcare providers. The Euro Heart Survey described the management of AF across 35 European countries in 2003-2004, in terms of diagnostic tests, interventions and drugs. ${ }^{9}$ Recently, the RecordAF Study, ${ }^{10}$ RealiseAF, ${ }^{11}$ EHPA $^{12}$ and GARFIELD ${ }^{13}$ Registries have provided further insights into the management of $\mathrm{AF}$ in normal clinical practice. These multinational registries are valuable but include a variety of models of healthcare provision across Europe.

A longitudinal understanding of the resource burden and treatment pathways specific to the management of $\mathrm{AF}$ in particular health systems is needed to inform future healthcare planning and policy development in this area. The primary objective of this observational, retrospective detailed case note review study was therefore to describe the use of primary and secondary care UK National Health Service (NHS) resources associated with the management of adult patients with AF. Secondary objectives were to describe the management pathway of patients with AF during a 3-year period from diagnosis and to describe the pattern of treatments throughout the clinical course.

\section{METHODS}

This study was conducted from March to August 2010 by retrospective review of the clinical records of patients diagnosed with $\mathrm{AF}$ in eight general medical practices in England $(n=7)$ and Wales $(n=1)$. Sites were purposively selected to ensure a good geographical spread, a mixture of urban and rural practices, a sample of practices which manage the anticoagulation of their own patients and a mixture of practices with and without a specialist interest in cardiology. Interested sites were then selected based on the practice list size and the capacity and resources to conduct the study. Brompton, Harefield and NHLI Research Ethics Committee (REC) and local management approval were given to conduct the study in the participating Primary Care Trusts.

The general practitioner (GP) investigator at each site identified candidate patients by searching the electronic patient records for currently registered patients aged $\geq 18$ years at the date of diagnosis, with a diagnosis of $\mathrm{AF}$ by Read $\operatorname{codes}^{14}$ for $\mathrm{AF}, \mathrm{AF}$ with flutter, persistent $\mathrm{AF}$, permanent $\mathrm{AF}$ and paroxysmal $\mathrm{AF}$ ). Patient consent was sought via post by the GP for access to their records by a researcher, from all eligible living patients with the exception of patients who were deemed unable to provide consent in the practice regardless of which GP managed their care (so that any potential effect on the study results of a GPwSI in cardiology was diluted). Patients who failed to return a signed consent form were assumed to have declined participation. The researcher then checked eligibility in the consenting patients against the remaining inclusion and exclusion criteria. Patients with secondary AF, those diagnosed $<12$ weeks before data collection or those with no diagnosis date were excluded. A sample size of 1000 patients
(500 initiation/maintenance) was chosen to ensure CIs of $\pm 5 \%$ on estimates of proportions, also allowing for a cluster effect of 1.2 due to the multicentre design, with an intracluster correlation of $0.35 \%$.

Anonymised-coded data were collected retrospectively from the primary care clinical records to describe resource use including AF-related prescribing, primary and secondary care visits and hospitalisations and demographics. For patients who had been recently diagnosed ( $<9$ months before data collection), data were collected on the first 12 weeks of management only ('initiation phase'). For patients diagnosed more than 3 years before data collection, data were collected on the most recent 3 years of management ('maintenance phase'), while patients diagnosed 9 months to 3 years before data collection provided data on both the initiation and maintenance phases. $\mathrm{CHADS}_{2}$ scores were calculated retrospectively for all patients at the end of the initiation phase and maintenance phase, using details from the clinical records.

Analyses were descriptive in nature using Microsoft Excel and SPSS according to a preagreed analysis plan. The main endpoint was NHS resource use, stratified by the initiation and maintenance phases of management, to provide a composite estimate of resource use throughout the treatment pathway. Resource use in the initiation phase is expressed per patient over the 12 weeks following diagnosis, while in the maintenance phase it is expressed per patient-year, adjusted pro rata for patients providing 6-12 months' data.

Data on drug treatments are expressed as treatments received at any time during the study and, in the initiation phase, to give a picture of how promptly treatments were started after diagnosis, in addition to the overall picture. As stroke risk scores were calculated at two points: end of initiation phase and end of maintenance phase, analysis of antithrombotic prescribing according to stroke risk is expressed as a proportion of patients on treatment at these two time points.

\section{RESULTS}

\section{Participating sites}

Eight general medical practices of 5-10 GPs with a median patient list size of 13440 (range 6500-15 500) participated, with three practices including a GP with a specialist interest (GPwSI) in the management of AF. Three centres provide an anticoagulation service to their own patients (one practice with GPwSI).

There were 1245 patients across all the participating practices which met the eligibility criteria and all were approached for consent. Data were collected from all $825(66.3 \%)$ consenting patients. The number of patients included per practice ranged from 82 to 151 . Data were available on the initiation phase from 310 patients and on the maintenance phase from 769 patients. Two hundred and fifty-four patients provided data on both phases. 


\section{Patient characteristics}

There were 462 male patients (56\%), and the mean patient age at diagnosis was 70.5 years (range 22.4-95.7). The mean age at diagnosis was 68.3 years in men (SD $11.1,95 \%$ CI 67.3 to 69.3 ) and 73.4 years in women (SD 10.4 , CI 72.2 to 74.4 ).

At the time of data collection, $363(44 \%)$ patients had a current diagnosis of permanent $\mathrm{AF}$ (ie, an ongoing long-term episode), 299 (36.2\%) paroxysmal AF (ie, recurrent episodes that self-terminate in $<7$ days), 55 (6.7\%) persistent $\mathrm{AF}$ (ie, recurrent episodes lasting $>7$ days) and $46(5.6 \%)$ patients first-detected $\mathrm{AF}$ (ie, only one diagnosed episode). Fourteen (1.7\%) patients had a record of two types of $\mathrm{AF}$ and $48(5.8 \%)$ patients had no record of AF type.

Seven hundred and twenty-six patients $(88 \%)$ had one or more relevant comorbidities; these included hypertension $(\mathrm{n}=472,57.2 \%)$, dyslipidaemia $(\mathrm{n}=206,25 \%)$, coronary artery disease $(\mathrm{n}=180,21.8 \%)$, stroke/transient ischaemic attack $(\mathrm{n}=140,17 \%)$, congestive heart disease $(n=131,15.9 \%)$, structural heart disease $(n=123,14.9 \%)$, diabetes $(n=111,13.5 \%)$, obesity (body mass index $>30$; $\mathrm{n}=106,12.8 \%)$ and respiratory disease $(\mathrm{n}=106,12.8 \%)$. Ninety-nine $(12 \%)$ patients had no recorded relevant comorbidity, $245(29.7 \%)$ patients had one comorbidity, $252(30.5 \%)$ had two comorbidities and $229(27.8 \%)$ had $>2$ comorbidities.

\section{Resource use}

Visits made by patients to NHS healthcare providers for $\mathrm{AF}$ are summarised in table 1.

\section{GP visits}

In the initiation phase, $253(82 \%)$ patients visited the GP practice at least once and $613(80 \%)$ did so in the maintenance phase. There were a mean of 2.4 (SD 2.2) primary care visits per patient during the initiation phase and 1.5 (SD 1.8) visits per patient-year in the maintenance phase. Two hundred and fifty $(81 \%)$ patients visited a GP in the initiation phase and $45(15 \%)$ visited a nurse. In the maintenance phase, $581(76 \%)$ patients visited a GP and $173(22 \%)$ visited a nurse.

\section{Hospital visits and admissions}

At least one hospital visit was made by 196 (63\%) patients in the initiation phase (mean 1.1 (SD 1.2) visits per patient) and $427(56 \%)$ patients in the maintenance phase (mean 0.8 (SD 1.0) visits per patient-year).

Outpatient clinic visits were made by 176 (57\%) patients in the initiation phase (mean 0.8 (SD 0.9) per patient) and $384(50 \%)$ in the maintenance phase (mean 0.6 (SD 0.9) per patient-year).

The mean length of hospital stay for all patients in the study was 2.2 (SD 6.1) days per patient during the initiation phase and 0.6 (SD 2.2) days per patient per year during the maintenance period.

For those patients admitted, the mean length of stay was 5.6 (SD 7.8) days in the initiation phase and 6.4 (SD 9.6) days in the maintenance phase.

\section{Cardiovascular drug treatments for AF}

Table 2 shows the distribution of cardiovascular drugs prescribed for rate/rhythm control in AF. Ninety-seven $(31.3 \%)$ patients in the initiation phase and 154/769

Table 1 Resource use: healthcare visits for atrial fibrillation

\begin{tabular}{|c|c|c|c|c|}
\hline \multirow[b]{2}{*}{ Visit type } & \multicolumn{2}{|c|}{ Initiation phase $(n=310)$} & \multicolumn{2}{|c|}{ Maintenance phase $(n=769)$} \\
\hline & $\begin{array}{l}\mathrm{N}(\%) \text { of } \\
\text { patients }\end{array}$ & $\begin{array}{l}\text { Mean number of visits } \\
\text { per patient (SD) }\end{array}$ & $\begin{array}{l}\mathbf{N}(\%) \text { of } \\
\text { patients }\end{array}$ & $\begin{array}{l}\text { Mean number of visits } \\
\text { per patient-year (SD) }\end{array}$ \\
\hline \multicolumn{5}{|l|}{ Primary care visits } \\
\hline Patients with any primary care visit* & $253(82 \%)$ & $2.4(2.2)$ & $613(80 \%)$ & $1.5(1.8)$ \\
\hline GP visits & $250(81 \%)$ & $2.3(2.1)$ & $581(76 \%)$ & $1.4(1.7)$ \\
\hline GP nurse visits & $45(15 \%)$ & $0.2(0.5)$ & $173(22 \%)$ & $0.2(0.3)$ \\
\hline \multicolumn{5}{|l|}{ Secondary care visits } \\
\hline Patients with any secondary care visit* & $196(63 \%)$ & $1.1(1.2)$ & $427(56 \%)$ & $0.8(1.0)$ \\
\hline Outpatient clinic & $176(57 \%)$ & $0.8(0.9)$ & $384(50 \%)$ & $0.6(0.9)$ \\
\hline Day care unit & $12(4 \%)$ & $0.0(0.2)$ & $52(7 \%)$ & $0.0(0.2)$ \\
\hline Emergency department visit & $26(8 \%)$ & $0.1(0.5)$ & $82(11 \%)$ & $0.0(0.2)$ \\
\hline Other secondary care visit & $3(<1 \%) \dagger$ & $0.0(0.1)$ & $2(<1 \%) \ddagger$ & $0.0(0.0)$ \\
\hline Inpatient admissions & $101(33 \%)$ & $0.4(0.7)$ & $139(18 \%)$ & $0.1(0.3)$ \\
\hline $\begin{array}{l}\text { Mean (SD) length of hospital stay } \\
\text { (days)—patients admitted }\end{array}$ & \multicolumn{2}{|c|}{$5.6(7.8)$ days, initiation period $(n=101)$} & \multicolumn{2}{|c|}{6.4 (9.6) days per patient-year $(n=139)$} \\
\hline $\begin{array}{l}\text { Mean (SD) length of hospital stay } \\
\text { (days)_all patients }\end{array}$ & \multicolumn{2}{|c|}{$2.2(6.1)$ days, initiation period $(n=310)$} & \multicolumn{2}{|c|}{$0.6(2.2)$ days per patient-year $(n=769)$} \\
\hline
\end{tabular}


Table 2 Rate/rhythm control for atrial fibrillation and antithrombotic medication during the initiation phase and maintenance phase

\begin{tabular}{|c|c|c|c|c|}
\hline & \multicolumn{2}{|l|}{ Initiation $(n=310)$} & \multicolumn{2}{|l|}{ Maintenance $(n=769)$} \\
\hline & Number of patients & Per cent & Number of patients & Per cent \\
\hline \multicolumn{5}{|l|}{ Rate/rhythm control treatment } \\
\hline$\beta$-blocker & 143 & 46.1 & 369 & 48.0 \\
\hline Sotalol $^{*}$ & 9 & 2.9 & 45 & 5.9 \\
\hline Class $1 \mathrm{c}$ antiarrhythmic agent & 5 & 1.6 & 31 & 4.0 \\
\hline Amiodarone & 15 & 4.8 & 63 & 8.2 \\
\hline Rate-limiting calcium antagonist & 22 & 7.1 & 78 & 10.1 \\
\hline Digoxin & 68 & 21.9 & 267 & 34.7 \\
\hline No rate/rhythm medication & 97 & 31.3 & 154 & 20.0 \\
\hline \multicolumn{5}{|l|}{ Antithrombotic medication } \\
\hline Antiplatelet & 124 & 40.0 & 268 & 34.9 \\
\hline Anticoagulant & 145 & 46.8 & 484 & 62.9 \\
\hline Both antiplatelet and anticoagulant & 34 & 11.0 & 78 & 10.1 \\
\hline Any antiplatelet and/or anticoagulant & 234 & 75.5 & 674 & 87.7 \\
\hline No antithrombotic medication & 76 & 24.5 & 95 & 12.4 \\
\hline
\end{tabular}

Totals of rows do not add up to the number of patients as patients may have received a combination and/or sequence of two or more treatments, that is, treatments are not mutually exclusive.

*Sotalol is a $\beta$-blocker with additional antiarrhythmic properties and so is shown separately from other $\beta$-blockers.

(20\%) patients during the maintenance phase did not receive any rate or rhythm control medication.

When patients started digoxin during the study $(\mathrm{n}=85)$, in $43(50.6 \%)$ cases, they did not receive a concomitant $\beta$-blocker or rate-limiting calcium-antagonist (RLCA) at the start of digoxin or within 28 days following.

In the initiation phase, $234(75.5 \%)$ patients received anticoagulant and/or antiplatelet thromboprophylaxis, as did $674(87.7 \%)$ patients in the maintenance phase.

There were $157(50.6 \%)$ patients with high stroke risk $\left(\mathrm{CHADS}_{2}\right.$ score $\left.\geq 2\right)$ at the end of the initiation phase, and $440(57.2 \%)$ patients at the end of the maintenance phase. Figure 1A,B shows the thromboprophylaxis prescribed according to stroke risk. One hundred and ninety-eight $(63.9 \%)$ patients with moderate or high stroke risk at the end of the initiation phase and 592 (77\%) patients at the end of the maintenance phase were receiving thromboprophylaxis.

Thirty-four patients $(11 \%)$ at 12 weeks after diagnosis and $78(10.1 \%)$ patients at the end of the maintenance phase were receiving an antiplatelet and an anticoagulant agent.

\section{DISCUSSION}

\section{Study patients}

In the 825 study patients, the mean age at diagnosis was lower for men (mean 68.3 years) than for women (mean 73.4 years), which is consistent with other research. $^{15}$

In the Euro Heart survey ${ }^{9}$ and RealiseAF study, ${ }^{11}$ diagnosis of $\mathrm{AF}$ was distributed $28 \%$ and $25 \%$ paroxysmal, $22 \%$ and $22 \%$ persistent and $29 \%$ and $46 \%$ permanent $\mathrm{AF}$, respectively. In our study, more patients had diagnoses of paroxysmal $(36 \%)$ and fewer of persistent $\mathrm{AF}$
(7\%), similar to the EPHA registry (38\% paroxysmal and $10 \%$ persistent AF). ${ }^{12}$ This may reflect the challenges in classifying or coding $\mathrm{AF}$ diagnosis, which has clinical significance as different treatment strategies are recommended for the various types of $\mathrm{AF}^{4}{ }^{6}$ Strategies are needed to ensure that diagnosis and coding are both accurate and standardised, to support appropriate patient management.

Our cohort of patients had lower rates of common comorbidities than was previously observed: for example, hypertension 57\%, $68 \%$ and $72 \%$; dyslipidaemia $25 \%, 42 \%$ and $39 \%$; coronary artery disease $22 \%$, $18 \%$ and $19 \%$; congestive heart disease $16 \%, 26 \%$ and $21 \%$ and diabetes $14 \%, 16 \%$ and $22 \%$ from this study and the RECORDAF ${ }^{10}$ and GARFIELD ${ }^{13}$ multinational registries, respectively. One possible explanation could be intercountry variability as these registries contain a relatively small proportion of patients from the UK. However, it is more likely that our cohort underrepresents comorbidities compared with the general population with $\mathrm{AF}$ in the $\mathrm{UK}$, as deceased patients and those unable to provide consent were not included for ethical reasons. These patients are perhaps more likely to be those with more comorbidities.

\section{Resource use}

As expected, most patients visited their GP at some point: $82 \%$ during the initiation phase and $80 \%$ in the maintenance phase. The primary care visit rates in this study were similar to the consultation rate seen in the Euro Heart survey (two consultations/year) ${ }^{9}$ Primary care visits were most often with a GP rather than a nurse, suggesting either that medical input is required, or there is no formal AF nurse-led service yet or most nurses are not prescribers. With appropriate training where necessary 


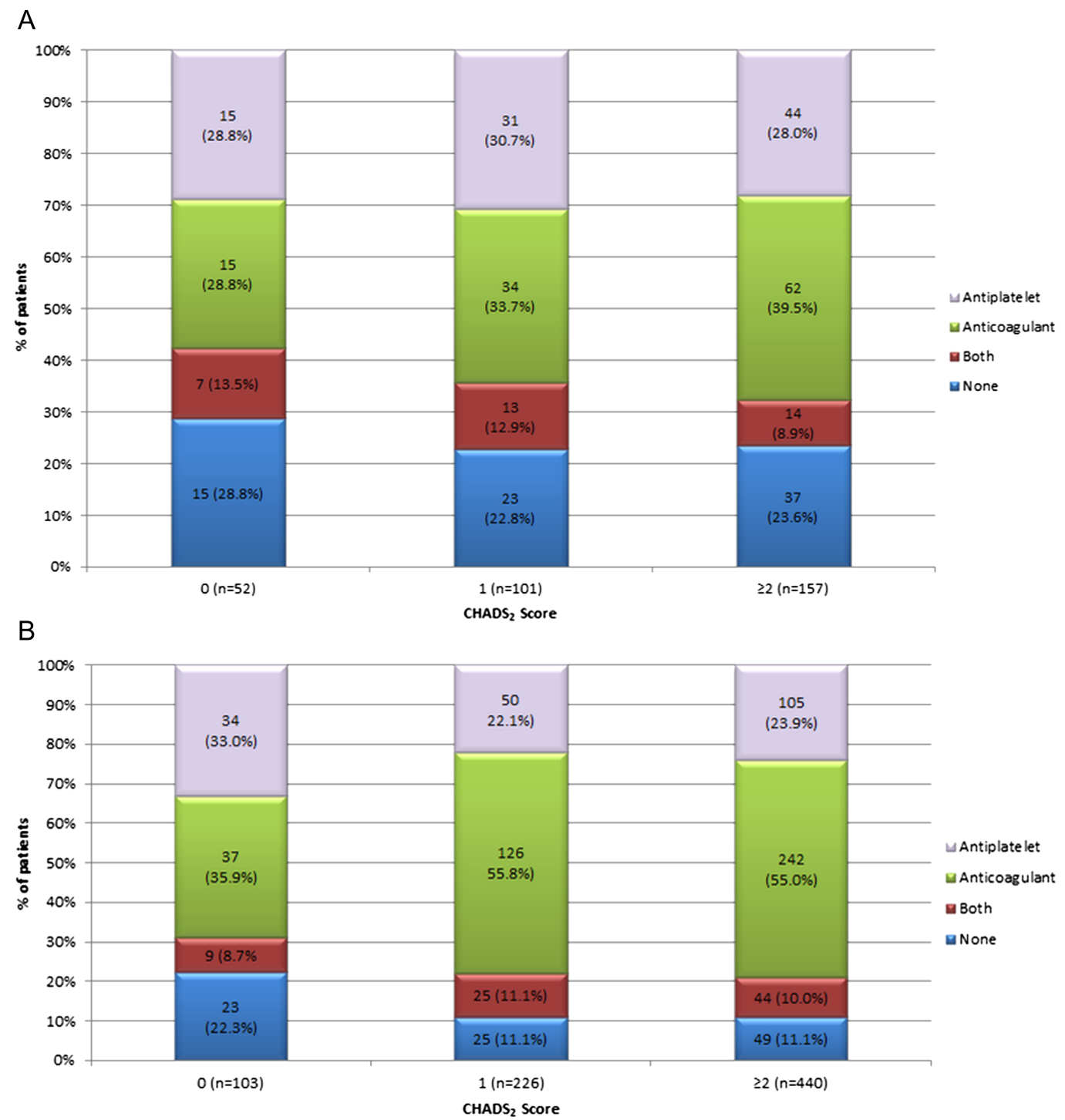

Figure 1 (A) Stroke prevention prescribed by $\mathrm{CHADS}_{2}$ score at the end of the initiation phase. (B) Stroke prevention prescribed by $\mathrm{CHADS}_{2}$ score at the end of the maintenance phase.

and with monitoring of patients' outcomes, increasing the involvement of practice nurses in managing patients in the maintenance phase could improve the efficiency of primary care management of AF.

Most patients had hospital visits (predominately outpatient clinic visits) in the initiation phase $(63 \%)$ and maintenance phase (56\%). A third of patients had an inpatient admission in the initiation phase and although in some cases this may be accounted for by diagnosis of $\mathrm{AF}$ during an admission for a different primary reason, one in six $(18 \%)$ patients were admitted to hospital for $\mathrm{AF}$ during the maintenance phase, similar to the EPHA registry ( $18.4 \%$ hospitalised in the previous year).${ }^{12}$ With mean lengths of stay of 5.6 and 6.4 days (initiation and maintenance phases, respectively) for those who were admitted, hospital care clearly represents a considerable resource burden. With the advent of GP commissioning, there may be scope for discussion with secondary care providers about the potential efficiencies to reduce the length of stay and appropriate ways for GPs to safely reduce avoidable hospital admissions for patients with AF.

\section{Management pathways}

Strategies for optimising cardiac function in $\mathrm{AF}$ are complex, with a number of treatment algorithms for the various types of $\mathrm{AF}$ available. ${ }^{4}{ }^{6} \beta$-Blockers are recommended first line for cardiac control for all types of $\mathrm{AF}^{6}$ but our results suggest that $\beta$-blocker use is low and lower than previously observed from the RecordAF and RealiseAF studies, ${ }^{10}{ }^{11}$ both during the first 12 weeks following diagnosis $(46.1 \%)$ and throughout maintenance ( $48 \%$ vs $68 \%^{11}$ and $61 \%{ }^{10}$ ). This apparent underuse of $\beta$-blockers may reflect poor tolerability and/or relative contraindications to their use, but this was not explored in this study, a limitation which should be addressed in any subsequent research or quality improvement work. 
The proportion of patients prescribed an RLCA $(7.1 \%$ and $10.1 \%$ patients in the initiation and maintenance phases, respectively) was not inconsistent with the RealiseAF (13.8\%) and RecordAF (9.7\%) studies ${ }^{10}{ }^{11}$ As RLCAs may be used instead of $\beta$-blockers for patients needing cardiac rate control, the results suggest that there is an opportunity to optimise treatment.

One-third $(34.7 \%)$ of patients received digoxin during the maintenance phase and a fifth $(21.9 \%)$ in the initiation phase, indicating that in practice digoxin is a treatment of choice. Only half $(50.6 \%)$ of the 85 patients who started digoxin during the study received a concomitant $\beta$-blocker or RLCA when starting digoxin treatment, as NICE recommends. ${ }^{6}$ While some digoxin monotherapy may be sufficient in sedentary patients or as an alternative to $\beta$-blockers/RLCA, where these firstline agents are not tolerated, it may also be a legacy of pre-NICE use of digoxin monotherapy first line for AF.

Almost a third $(31.3 \%)$ of all patients during the initiation phase and $20 \%$ of patients during the maintenance phase did not receive any rate/rhythm control treatment, more than in the RealiseAF study (5.1\%), although RealiseAF was a cross-sectional study. Although the reasons for this were not recorded, patient refusal and contraindications such as bradycardia and hypotension may account for a proportion. In some patients, the physician may have felt that rate/rhythm control was not warranted due to the asymptomatic nature of the AF. Reasons for prescribing are rarely documented in medical records, while reasons for not prescribing are even more rarely documented. Lack of insight into reasons for withholding rate/rhythm control is a limitation of the retrospective design of this study. A prospective quality improvement project in this area would not only provide an opportunity to clinicians to document such reasons but also, by focusing attention on the subject, possibly contribute to an improvement in evidence-based management of AF for the direct benefit of patients.

\section{Stroke prevention}

Although NICE recommends that antithrombotic therapy should be started with minimal delay in newly diagnosed $\mathrm{AF}^{6}{ }^{6}$ one quarter $(24.5 \%)$ of patients did not receive any antithrombotic therapy in the initiation phase. This apparent underuse of thromboprophylaxis was also seen to a lesser degree in patients in the maintenance phase; $12.4 \%$ of patients did not receive any antithrombotic therapy during this period. This is more than in the EHPA study $(5.6 \%) .{ }^{12}$ Underprescribing of antithrombotics was more prevalent than overuse: only $11 \%$ of patients in the initiation phase and $10.1 \%$ in the maintenance phase were receiving an antiplatelet and an anticoagulant. Nevertheless, this does need to be addressed as coprescription of an antiplatelet and warfarin increases the risk of bleeding for no additional stroke rate reduction. ${ }^{1617}$

\section{Stroke prevention according to stroke risk}

When the $\mathrm{CHADS}_{2}$ score was calculated, approximately half of all patients were at high risk of stroke (ie, $\mathrm{CHADS}_{2}$ score $\geq 2 ; 50.6 \%$ at the end of the initiation phase, $57.2 \%$ at the end of the maintenance phase). Over half of the patients at high risk of stroke at the end of the maintenance phase, $(55 \%)$ were receiving anticoagulation therapy as recommended, but a quarter $(23.9 \%)$ were receiving antiplatelet therapy and $11 \%$ were not receiving any thromboprophylaxis. This apparent underprescribing of anticoagulation in patients at high risk of stroke may be partly explained by warfarinrelated factors, including intolerance, history of bleeding episodes and/or patient preference. However, this observation warrants further action, as warfarin is significantly more effective than aspirin for stroke prevention. ${ }^{18-21}$ These results are similar to the observations from a survey in 583 UK practices in which $53 \%$ of patients were receiving anticoagulants in $2010 .^{22}$

Over half of the patients $(57.7 \%$, initiation phase; $55.3 \%$, maintenance phase) with low stroke risk (ie, $\mathrm{CHADS}_{2}$ score $=0$ ) were appropriately prescribed aspirin or no antithrombotic therapy, as was recommended during the study observational period, ${ }^{6}$ although recently it is acknowledged that "no antithrombotic therapy', rather than aspirin, should be the default for patients with a low risk of stroke and absence of risk factors. ${ }^{23}$ However, $28.8 \%$ of patients at low risk in the initiation phase and $35.9 \%$ in the maintenance phase were prescribed an anticoagulant. In the absence of any other reason for anticoagulation, this may be putting these patients at unnecessarily increased bleeding risk and burden of monitoring. The management of $\mathrm{AF}$ and stroke prophylaxis has been identified as areas for improvement within the NHS. The introduction of the $\mathrm{CHADS}_{2}$ score into the NHS Quality Outcomes Framework, ${ }^{7}$ the publication of the NHS Improvement document, ${ }^{24}$ supporting the commissioning of AF services and the NICE guidance on the new oral anticoagulant dabigatran ${ }^{25}$ will all be important in ensuring that patients' stroke risk is reviewed and appropriate antithrombotics prescribed.

The primary strength of this study is that it describes recent 'real world' UK clinical practice in primary care management of AF. It has limitations, however: the retrospective methodology relies on the quality and completeness of clinical records. It also assumes that the results for those patients providing consent are representative of all patients with $\mathrm{AF}$ at the practices, as the characteristics for non-consenting patients were not collected to allow assessment of whether consenting and nonconsenting patients differed in any important respects. Although the sample was a majority $(66 \%)$ of all eligible patients overall, the sample size achieved was lower than expected for the initiation group but higher for the maintenance group and is unexplained.

The study was not conducted using precollected anonymised data from large databases of coded GP records 
data because detailed data were needed from free-text fields in patients' clinical case notes in order to understand the reasoning for clinical decisions. The required linked and detailed data were not available via large database sources at the time the study was conducted, although studies of AF using these less detailed data have been conducted recently. ${ }^{26}$ These sources have been developed to include linkage between primary and secondary care datasets and precollected, anonymised data, not requiring individual patient consent for its use in research database studies, but allowing the inclusion of data on deceased patients or those with end-stage terminal illness. The terms of the REC approval for our study did not allow the inclusion of data from such patients, so the resource use we describe may be an underestimate due to the exclusion of these potentially resource-intensive patients. This assumption is supported by the lower prevalence of comorbidities in our sample, compared with previous observational samples of patients with $\mathrm{AF}$, since the comorbidities themselves are likely to be significant predictors of healthcare resource use independently of the AF.

\section{CONCLUSION}

This study shows that the management of AF in UK primary care involves considerable healthcare resource use, mainly from referrals and admissions to hospital. As the burden of AF is likely to increase, further work is needed to identify potential efficiencies and inform healthcare planning and policy development in this area.

The results suggest that some GPs may have difficulty in applying appropriate diagnostic labels to patients with $\mathrm{AF}$ and that this may be contributing to inappropriate prescribing decisions. Apparent underprescribing of $\beta$-blockers, RLCAs and thromboprophylaxis and the high prevalence of digoxin monotherapy warrant prospective research and quality improvement work to investigate the reasons for these apparent deviations from guidelines and support GPs to move towards more evidence-based prescribing for AF, for the benefit of patients.

Acknowledgements The authors wish to thank the following local investigators who recruited patients in the study and for their contribution of data to this study: Dr John Ryan - The Alverton Practice, Penzance, UK. Dr John JonesCyncoed Medical Centre, Cardiff, UK. Dr Warwick Coulson—Albany House Medical Centre, Wellingborough, UK. Dr Trevor Gooding-The Atherstone Surgery, Atherstone, UK. Dr Barbara King - Carterknowle and Dore Medical Practice, Sheffield, UK. The Ringmead Medical Practice, Bracknell, UK. Carmel Medical Practice, Darlington, UK. Park Surgery, Chandlers Ford, UK.

Contributors GK, CA, SH, RD and AF were involved in the planning, conduct of the research study, interpretation and reporting of the results and met the criteria of authorship.

Funding The research was funded by Sanofi UK, One Onslow Street, Guildford GU1 4YS, UK.

Competing interests GK reports receiving consulting fees from Sanofi UK; CA reports receiving consulting fees from Sanofi UK; $\mathrm{SH}$ is a full-time employee of Sanofi UK; RD is a full-time employee of $\mathrm{pH}$ Associates Ltd under commission by Sanofi UK.
Ethics approval Brompton, Harefield and NHLI Research Ethics Committee.

Provenance and peer review Not commissioned; externally peer reviewed.

Data sharing statement All data relating to the study are intended to be in the public domain. An abstract from data resulting from this research, which is related to the health economic cost of management of Atrial Fibrillation in the NHS, was presented at the International Society for Pharmacoeconomics and Outcomes Research (ISPOR) 15th Annual European Congress, Berlin, November 2012, and the related manuscript will be submitted to a health economic focused journal. The study data are in the custodianship of $\mathrm{pH}$ Associates on behalf of the Study Sponsor. The Study Sponsor is open to receiving requests for the sharing of data.

Open Access This is an Open Access article distributed in accordance with the Creative Commons Attribution Non Commercial (CC BY-NC 3.0) license, which permits others to distribute, remix, adapt, build upon this work noncommercially, and license their derivative works on different terms, provided the original work is properly cited and the use is non-commercial. See: http:// creativecommons.org/licenses/by-nc/3.0/

\section{REFERENCES}

1. Davis RC, Hobbs FD, Kenkre JE, et al. Prevalence of atrial fibrillation in the general population and in high-risk groups: the ECHOES study. Europace 2012;14:1553-9.

2. Kannel WB, Wolf PA, Benjamin EJ, et al. Prevalence, incidence, prognosis and predisposing conditions for atrial fibrillation: population-based estimates. Am J Cardiol 1998;82:2N-9N.

3. Naccarelli GV, Varker H, Lin J, et al. Increasing prevalence of atrial fibrillation and flutter in the United States. Am J Cardiol 2009;104:1534-9.

4. Camm A, Kirchhof P, Lip G, et al. Guidelines for management of atrial fibrillation: the task force for the management of atrial fibrillation of the European Society of Cardiology (ESC). Guidelines for the management of atrial fibrillation. Eur Heart J 2010;31:2369-429.

5. Wolf PA, Dawber TR, Thomas HE Jr, et al. Epidemiologic assessment of chronic atrial fibrillation and risk of stroke. The Framingham Study. Neurology 1978;28:973-7.

6. National Institute for Health and Clinical Excellence (NICE). Clinical Guideline CG36-Atrial Fibrillation: The management of atrial fibrillation. 2006. http://www.nice.org.uk/CG36 (accessed 13 Jun 2013).

7. British Medical Association. QOF Guidance 2013/14 QOF Changes. http://bma.org.uk/practical-support-at-work/contracts/ independent-contractors/qof-guidance (accessed 12 Jun 2013).

8. Gage BF, Waterman AD, Shannon W, et al. Validation of clinical classification schemes for predicting stroke: results from the National Registry of Atrial Fibrillation. JAMA 2001;285:2864-70.

9. Nieuwlaat R, Capucci A, Camm AJ, et al. Atrial fibrillation management: a prospective survey in ESC Member Countries: The Euro Heart Survey on Atrial Fibrillation. Eur Heart J 2005;26:2422-34.

10. Le Heuzey J-Y, Breithardt G, Camm J, et al. The RecordAF study: design, baseline data, and profile of patients according to chosen treatment strategy for atrial fibrillation. Am J Cardiol 2010;105:687-93.

11. Steg PG, Alam S, Chiang C-E, et al. Symptoms, functional status and quality of life in patients with controlled and uncontrolled atrial fibrillation: data from the RealiseAF cross-sectional international registry. Heart 2012;98:195-201.

12. Cohen A, Dallongeville J, Durand-Zaleski I, et al. Characteristics and management of outpatients with history of or current atrial fibrillation: the observational French EPHA study. Arch Cardiovasc Dis 2010;103:376-87.

13. Kakkar AK, Mueller I, Bassand J-P, et al. Risk profiles and antithrombotic treatment of patients newly diagnosed with atria fibrillation at risk of stroke: perspectives from the International, Observational, Prospective GARFIELD Registry. PLOS ONE 2013;8: e63479.

14. NHS Connecting for Health: Read Codes. http://www. connectingforhealth.nhs.uk/systemsandservices/data/uktc/readcodes (accessed 13 Jun 2013).

15. Humphries K, Kerr C, Connolly S, et al. New-onset atrial fibrillation sex differences in presentation, treatment, and outcome. Circulation 2001;103:2365-70.

16. DiMarco J, Flaker G, Waldo A. Factors affecting bleeding risk during anticoagulant therapy in patients with atrial fibrillation: observations from the Atrial Fibrillation Follow-up Investigation of Rhythm Management (AFFIRM) Study. Am Heart J 2005;149:650-6. 
17. Lip G, Boos C. Antithrombotic treatment in atrial fibrillation. Heart 2006;92:155-61.

18. Mant J, Hobbs F, Fletcher K, et al. Warfarin versus aspirin for stroke prevention in an elderly community population with atrial fibrillation (the Birmingham Atrial Fibrillation Treatment of the Aged Study, BAFTA): a randomised controlled trial. Lancet 2007;370:493-503.

19. Aguilar MI, Hart R, Pearce L. Oral anticoagulants versus antiplatelet therapy for preventing stroke in patients with non-valvular atrial fibrillation and no history of stroke or transient ischemic attacks. Cochrane Database Syst Rev 2007;3:CD006186.

20. Saxena R, Koudstaal P. Anticoagulants versus antiplatelet therapy for preventing stroke in patients with non-rheumatic atrial fibrillation and a history of stroke or transient ischemic attack. Cochrane Database Syst Rev 2004;4:CD000187.

21. Hart RG, Pearce LA, Aguilar MI. Meta-analysis: antithrombotic therapy to prevent stroke in patients who have nonvalvular atrial fibrillation. Ann Intern Med 2007;146:857-67.

22. Holt TA, Hunter TD, Gunnarsson C, et al. Risk of stroke and oral anticoagulant use in atrial fibrillation: a cross-sectional survey. $\mathrm{Br} J$ Gen Pract 2012;62:e710-17.
23. Camm JA, Lip GYH, De Caterina R, et al. 2012 focused update of the ESC Guidelines for the management of atrial fibrillation. An update of the 2010 ESC Guidelines for the management of atrial fibrillation. Developed with the special contribution of the European Heart Rhythm Association. Eur Heart J 2012;33: 2719-47.

24. NHS Improvement. Anticoagulation for Atrial Fibrillation-a simple overview to support the commissioning of quality services. 2011. http://www.improvement.nhs.uk/heart/Heartresources/publications. aspx (accessed 12 Jun 2013).

25. National Institute for Health and Care Excellence (NICE). Dabigatran etexilate for the prevention of stroke and systemic embolism in atrial fibrillation (TA249). London, England: NICE, 2012. http:// publications.nice.org.uk/dabigatran-etexilate-for-the-prevention-ofstroke-and-systemic-embolism-in-atrial-fibrillation-ta249 (accessed 12 Jun 2013)

26. Gallagher AM, Rietbrock S, Plumb J, et al. Initiation and persistence of warfarin or aspirin in patients with chronic atrial fibrillation in general practice: do the appropriate patients receive stroke prophylaxis? J Thromb Haemost 2008;6:1500-6. 